\title{
Notes on Terminology
}

The words we use have tremendous power to shape our perceptions and our reality. Nowhere is this truer than in the field of psychiatry. Here words affect our very sense of who we are and, by making our choices seem limited, can have real and sometimes disastrous effects on our lives.

I would have prefered to use quotation marks for every occurrence of the terms "mental health," "mental illness," or "mentally ill" in order to avoid granting even subliminal credibility to the medical model I discuss in Chapter Two. For editorial reasons the quotes have been omitted, but please read the words as if they were in quotes.

When it comes to speaking about people with psychiatric labels, including myself, none of the currently fashionable terms, such as "psychiatric survivor," "recipient," "client," or "person with a psychiatric disability" is broad enough to apply to such a diverse group of people, and "consumer" has connotations of choice that are simply wishful. Whether we came into contact with psychiatry voluntarily or involuntarily, we were all once mental patients. Plus, everyone understands that term. Therefore I have chosen to use "mental patient." 



\section{DOCTORS OF DECEPTION}


